\title{
Não é apenas sobre o funk ostentação: narrativas midiáticas e experiências do sensível em cotidianos de vulnerabilidade
}

\author{
It's not just about funk ostentação: media narratives \\ and sensitive experiences on vulnerability contexts
}

\begin{abstract}
Rosamaria Luiza de Melo Rocha | PPGCOM-ESPM
Doutora em Ciências da Comunicação pela ECA/USP com pós-doutorado em Ciências Sociais/ Antropologia na PUCSP. É professora titular e pesquisadora do Programa de Pós-Graduação em

Comunicação e Práticas de Consumo da ESPM/SP. Bolsista produtividade em pesquisa CNPq.
\end{abstract}

E-mail: rlmrocha@uol.com.br

\begin{abstract}
Simone Luci Pereira | PPGCOM-UNIP Mestre em História e Doutora em Ciências Sociais. Realizou Pós-doutorado em Música, junto ao GP Musica Urbana No Brasil - UNIRIO (bolsista POsDoc Senior da FAPERJ). Atualmente realiza pesquisa de pós-doutorado no Progranma Postdoctoral en Ciencias Sociales, Ninez y Juventude, na Red CLACSO. Professora e pesquisadora do PPG Comunicação e Culturas Midiáticas da UNIP. Professora e pesquisadora colaboradora do PPG Comunicação e Praticas do Consumo da ESPM.

E-mail: simonelp@uol.com.br
\end{abstract}

\begin{abstract}
Aline Borges Rezende | PPGCOM-UNIP Mestranda em Comunicação e Práticas de Consumo pela Escola Superior de Propaganda e Marketing -SP. Participa do grupo de pesquisa Clacso e também do grupo Juvenália, vinculado ao CNPQ. Bolsista Capes.

E-mail: alineespm@gmail.com
\end{abstract}

\begin{abstract}
Resumo
Para abordar a relação entre experiência e cotidiano, o artigo analisa modos de narrar e de consumir cultura midiática, refletindo sobre as ambivalências e polissemias das narrativas do entretenimento. As autoras entendem que elas se completam e se efetivam no cotidiano, e implicam em práticas de olhar e de escuta que se realizam mediante dinâmicas performativas. As experiências do sensível e as táticas do cotidiano são, assim, aspectos centrais à compreensão de um fenômeno complexo e paradoxal, o funk ostentação. Esta expressão cultural da periferia é utilizada como observatório de fluxos e possíveis táticas de enfrentamento sensível de vivências cotidianas, de vulnerabilidade, precariedade e limiaridade.
\end{abstract}

Palavras-Chave: Experiência sensível; cotidiano; narrativas midiáticas.

\begin{abstract}
To address the relationship between experience and daily life, the article looks forward the ways of narrating and consuming media culture, reflecting on the ambivalence and polysemy of entertainment narratives. The authors understand that they are completed and become effective in everyday life and entail looking at and listening practices that take place by performing dynamics. The experiences of the sensible and the everyday tactics are thus key aspects to understanding a complex and paradoxical phenomenon, named funk ostentação. This cultural expression of the periphery is used as an observatory of flows and possible sensitive tactics that faces the everyday experiences of vulnerability, precariousness and liminality
\end{abstract}

Keywords: Sensory experience; everyday life; media narratives 
Interessa-nos neste artigo explorar algumas conexóes entre cotidiano $e$ experiência sensivel a partir de uma mirada eminentemente comunicacional. Partindo de vivências de campo relatadas e analisadas por Aline Rezende, e dialogando com os estudos sobre cenas pós-periféricas que têm mobilizado Rose de Melo Rocha e Simone Luci Pereira, percorreremos as pistas deixadas pelos seguintes problemas de investigação: quais ordens e "partilhas do sensível” (RANCIÈRE, 2009) são tecidas pela presença performativa de narrativas midiáticas de entretenimento no cotidiano daqueles que experimentam diariamente situaçôes de vulnerabilidade extrema? Quais as possíveis mediaçóes entre as cenas representadas nas narrativas midiáticas e a realidade cotidiana daqueles que as consomem? Regimes afetuais diversos perpassam o consumo de imagens e sonoridades midiatizadas, de um lado, e a midiatização do cotidiano dos receptores de tais audiovisualidades, de outro? Como e sob quais condiçôes eles se aproximam? É possível distinguir teoricamente níveis de apropriação e diferentes princípios de vinculação articulados ao ciclo de consumo audiovisual e ao circuito do entretenimento (a produção de subjetividades e de sensibilidades plurais e a reiteração de identidades profundamente conservadoras, por exemplo)? Que tipo de enunciação pública promovem as narrativas midiáticas por nós estudadas e em que medida ela estimula práticas de recepção dotadas de politicidade? ${ }^{1}$ Para caminhar junto às indagaçóes que derivam destas perguntas centrais e dos aspectos que agora serão abordados, nos valemos de uma agenda tripartite: como chaves conceituais, tomamos o eixo reflexivo proposto neste dossiê, a saber, o de experiência (sensível) e cotidiano; em termos empíricos, recorremos a observações do consumo de funk ostentação por crianças e adolescentes moradores de uma região periférica da baixada santista, no estado de São Paulo; finalmente, como articulador epistêmico que tece os platôs anteriores, nos valemos das teses de Rincón sobre o modo de narrar da sociedade do entretenimento (RINCÓN, 2006) e sobre a ideia das culturas bastardas (RINCÓN, 2015).

É-nos particularmente auspiciosa a proposta de Amado e Rincón (2015) ao postular "novos modos de discursos para pensar a comunicação" (AMADO e RINCÓN, 2015, p.5), pois é justamente isto que buscamos ao questionar, de um lugar sensível e sensibilizado, fenômenos tão complexos como o funk ostentação, mas também os fluxos e "rolezinhos". Em direção similar, uma visada importante se apresenta. Ao analisar produtos advindos do "ostentação", recusamos leituras rígidas, ortodoxas ou anacrônicas que, ainda que o possam descrever em detalhes ideológicos ou em seus meandros alienantes e reprodutivistas, deixam escapar a tessitura intricada e os elementos paradoxais que compóem não apenas esta narrativa audiovisual, mas, o que é fundamental, os seus contextos de recepção e os circuitos de celebrização, distinção e subjetivação a ela atinentes.

Fugindo de derivaçôes tecnicistas e midiacentristas, evitamos interpretaçôes que, por exemplo, se ativessem exclusivamente às qualidades formais ou aos conteúdos dos vídeos, em si mesmos. ${ }^{2}$ Ao contrário, como estudiosas do consumo, temos claro que narrativas midiáticas (como, aliás, todos os fenômenos comunicacionais) são dinâmicas, processuais, reticulares, 
conjunturais. Ou seja, seu "em si” é dado pela "experiência-acontecimento" que articula o plano da produção ao da recepção e decalca o consumo com as artimanhas da mediação, dos usos, das releituras. É, portanto, em rede e em fluxo que se constrói nosso olhar, e isto nos leva a falar em práticas culturais (perpassadas pelo consumo), muito mais do que em produtos de consumo (cultural, por exemplo).

Reconhecer a complexidade do fenômeno não significa se furtar à análise crítica das paisagens simbólicas que resultam do acontecimento midiático, isto porque sabemos que nelas pode reverberar a palavra de ordem normativa, excludente, sedutoramente ciosa de azeitar as engrenagens do status quo. Mas significa, sem dúvida, e retomamos aqui o pensamento barberiano, saber olhar outros olhares, ou, dito de outra forma, saber que o olhar do pesquisador, com todos seus escrutínios, protocolos e aparatos reflexivos, é apenas um modo de observar, sejam as discursividades midiáticas, sejam as narrativas de sujeitos que em suas práticas cotidianas se apropriam destas discursividades, tornando-as parte de um modo de vida, de ser no mundo, ou, em alguns casos, de uma tática de sobrevivência psíquica em contextos limítrofes ${ }^{3}$.

\section{Sobre algumas ordens da experiência sensível}

Chegamos agora a outro ponto de nosso argumento. Caberá aqui apresentar aos leitores princípios de observação que se agregam aos anteriormente enunciados e respondem a uma preocupação: a que nos referimos ao falar em experiência sensível?

Esta noção se aplica à análise do consumo de narrativas audiovisuais e também irá compor a percepção dos meandros próprios à incorporação performativa de discursos e formas midiáticas no cotidiano de habitantes específicos de nossas cidades. Tomar este princípio como norte nos leva ainda a perceber como, no lugar narrativo construído por audiovisualidades midiáticas, todo um mapa de açôes, sensaçóes e afetaçôes está sendo engendrado.

Tomando por inspiração o que propõe Rincón (2006), temos que, nas culturas midiáticas, "os meios de comunicação são fundamentalmente narradores de mundo e [...] o entretenimento é o horizonte do sentido midiático" (RINCÓN, 2006, p.6; tradução nossa). Seja por sua força mimética, seja por seu poder de arrebatamento (e neste caso as audiovisualidades se destacam), as linguagens que brotam destes meios de significação irradiam no cotidiano, mas não o fazem, como insiste Rincón, em uma avalanche totalizante que justificasse posturas deterministas sobre elas.

Vale ressaltar que uma experiência narrativa como a do funk ostentação articula vivências de sensibilidade e de sentido que, já em sua gênese, embaralham as fronteiras entre meios massivos e mídia maciça, entre mainstream e celebrizações periféricas, entre tensionamento social e de classe e captura conformista. Esta sensibilidade de fronteira, limiar, parece-nos refletir e refratar a experiência cotidiana das crianças e adolescentes em situaçáo de vulnerabilidade e precariedade social que são fiéis consumidoras dos clipes de sucesso e do imaginário de fama e superação associados às estrelas do "ostentação". "As cidadanias celebrities": 
reconhecem que o sujeito popular, também, quer existir no mainstream e quer contar em seus próprios termos porque de nada lhe serve ser bom cidadão se ninguém o reconhece. Quer-se existir nestas visualidades leves para aumentar a autoestima pública e, também, para incomodar, ferrar e sacanear ao mainstream em suas estéticas e políticas (RINCÓN, 2015, p. 38; tradução nossa).

Objetos de estudo como este participam do que Rincón (2015) associa à subversão das ordens estabelecidas e, deste ponto de vista, trata-se de um deslocamento tanto do lugar da experiência sensível quanto dos pertencimentos cotidianos. Um novo modo de narrar e de consumir cultura midiática se anuncia aí, em práticas de olhar e de escuta que se realizam mediante dinâmicas performativas - canta-se e coreografa-se o funk ostentação na atribuição de sentido a interaçóes do dia-a-dia, como narrativa de partilha que ressignifica os pertencimentos e como recurso imaginário que ancora e articula socialidades esgarçadas. Como nota Herschmann (2015), "a música/sons como forma de entretenimento são algumas das principais 'forças mobilizadoras' do mundo contemporâneo [...], são pilares dos 'modos de existência' e dos 'projetos de vida' no milênio que começa”' (HERSCHMANN, 2015, p. 47; tradução nossa).

Reconhecendo a centralidade midiática - e sua potência narrativa Rincón (2006) pergunta-se inúmeras vezes sobre as possibilidades que as culturas midiáticas encerram na produção de novas experiências de subjetivação, de cidadania e de comunidade. $\mathrm{O}$ autor não desconhece que referencializar a vida unicamente em narrativas advindas dos meios pode resultar em precarizaçáo dos sentidos - e da experiência, poderíamos acrescer. Contudo, ele insiste, há nestas formas de narrar um apelo ou ordem afetual, uma ritualística, que pode ser pedagógica, ensejando a reconstrução de vínculos cotidianos ou, até mesmo, ensinando a vincular. O plano dos "afetos comuns" seria a base desta que aqui chamamos uma "utopia do entretenimento", na qual o direito a ter uma vida divertida, entretida, como propõe Rincón, é uma estratégia (narrativa) de lutar contra o tédio e a desesperança e escapar das misérias da vida (RINCÓN, 2006).

Rancière (2009) compreende a política como forma da experiência (do sensível) que envolve visibilidade e competências enunciativas: "A política ocupa-se do que se vê e do que se pode dizer sobre o que é visto, de quem tem competência para ver e qualidade para dizer, das propriedades do espaço e dos possíveis do tempo" (RANCIÈRE, 2009, p.18).

Sabemos que o mesmo autor, ao defender a ideia de uma "partilha do sensível”, mira e acerta de modo certeiro os pilares hierarquizantes das teorias clássicas da representação, nelas incluídos os debates estéticos e as configuraçôes políticas modernas. A munição que propicia esta experiência iconoclasta (e de emancipação) está no que ele associa à emergência avassaladora do anônimo, do "qualquer um", do ordinário, do banal. A "nova ficcionalidade”, argumenta Rancière, "é, antes de mais nada, uma maneira de dar sentido ao universo 'empírico' das ações obscuras e dos objetos banais" (RANCIÈRE, 2009, p. 55). Nesta perspectiva, "os enunciados políticos ou literários fazem efeito no real" e definem "regimes de intensidade sensível", assim como "atos estéticos como configuraçôes da experiência [...] induzem novas formas de subjetividade política” (RANCIĖRE, 2009, p. 59; p.11). 
Identificamos certa dialogia entre estas argumentaçóes e o conceito de culturas bastardas (RINCÓN, 2015), impostura reflexiva que se presta justamente a nomear "o sujo, o impuro, o promíscuo porque não têm pai reconhecido; por isso são herança de muitos pais e imitam de todas partes para tentar ter uma identidade ou, ao menos, um estilo próprio" (RINCÓN, 2015, p. 28). Contudo, e isto é fundamental, "têm sentido porque se sabem filhas de uma só mãe à qual adoram, odeiam e celebram em simultâneo: a cultura local, a própria" (idem).

Obviamente, Rincón (2015) está preocupado com o que ele nomeia a reinvenção do conceito do popular, caro a tantos estudos comunicacionais, e é dele que parte para chegar à ideia do bastardo e das cidadanias celebrities - "ou essas maneiras pop-líticas de existir" (RINCÓN, 2015, p.23). As sensibilidades inclusivas que podem daí emergir seriam ambíguas, ambivalentes, ilegítimas e impuras e é interessante que o autor cite a Ernesto Laclau ao abordar o referente cultural do "popular politizado" (RINCÒN, 2015, p.30), Laclau (2008), o inquieto dublê de guerreiro e advogado do diabo das propostas contemporâneas de reinvenção da política. Isto porque Rincón provoca (involuntariamente?) a Laclau, e o faz ao reconhecer que o "popular bastardizado é um quilombo [...] de tudo: autenticidade, resistências, submissões, cumplicidades, inovações e aberraçôes." (RINCÓN, 2015, p.33).

Se uma superfície é "uma forma de partilha do sensível", como diz Rancière (2009, p.21), podemos identificar o relevo de tensóes e composiçóes afetuais e imaginárias que articula, na experiência cotidiana, a superfície de clipes do funk ostentação à superfície geográfica dos becos que retrata e dos corpos que representa, por apresentação visível ou supressão intencional, e neste caso não se trata de uma expressão de veracidade, mas propriamente de um universo ficcional que ao mesmo tempo narra e ressignifica tais experiências e cotidianos.

Tomar a experiência sensível como recurso de aproximação e análise das práticas de consumo midiático - englobando a produção, as dinâmicas de veiculação, os usos e os contextos de recepção e a relação imagem/ imaginário - forçosamente leva a um rechaço de interpretaçôes que se restrinjam a um viés reprodutivista. São questionamentos de ordem ética os que emergem da derivação proposta, levando-nos a perguntar, em primeiro lugar, sobre uma ética possível na produção e recepçáo destas narrativas. Em segundo lugar, pensar nestes termos implica a consideração de que a economia política (da mídia) convive com a economia simbólica (dos usos, das sensibilidades e das vinculaçóes).

Em resumo, há uma “imagética do consumo” (ROCHA, 2009) plástica, maleável, plural, coabitando com as mais duras e inflexíveis narrativas do capital, o que coloca em convivência (e, podemos facilmente supor, em constante confronto) regimes de vinculação e ordens do sensível bastante díspares ou contraditórias. E é no cotidiano que estas tensôes se explicitam e se rearranjam, isto ao considerarmos, como se verá no tópico seguinte, que ele é muito mais complexo e tático do que supóem as teorias da reprodução social 


\section{Sobre algumas possibilidades de se pensar o cotidiano}

O estudo do cotidiano vem mostrando-se como campo de possibilidades de análise social e cultural. Mais ainda, contribui para uma crítica a alguns parâmetros epistemológicos das Ciências Humanas, ao trazer um deslocamento do foco de análise dos discursos normativos e de concepçôes ilustradas e legítimas de cultura, para voltar a atenção para outros sujeitos, outras práticas, outros modos de narrar e outras linguagens que, mais fragmentárias e dispersas, tantas vezes são encaradas como banais, triviais, e por isso equivocadamente percebidas como fruto da mera reprodução social.

Formulando um pensamento no qual a vida cotidiana é vista como algo que envolve margens de possibilidades no equilíbrio entre individualidade e generalidade, Agnes Heller (1985) argumentava - dentro do debate marxista ainda nos anos $1960^{4}$ - que a ordenação da cotidianidade seria um fenômeno nada cotidiano, podendo, sim, ser encarado como algo essencialmente político. Ainda num revisionismo do marxismo, buscando um desvio epistemológico que trouxesse a cultura para o centro da análise (e não como mero reflexo da base econômica), os estudiosos do Centre of Contemporary Cultural Studies (CCCS) de Birmingham viam no cotidiano um lócus importante de análise das práticas culturais, dando destaque para a cultura como modo de vida total (GOMES, 2011), em que o ordinário da vida dos homens em seu dia a dia recebe particular atenção.

Nas reflexôes no campo da História na França da década de 1930, os pesquisadores dos Analles também contribuíram para um olhar que descortinou o cotidiano para além da história oficial e dos grandes personagens. Numa tentativa de desvencilhar as análises de idealidades abstratas e conceitos teóricos acabados, buscavam as realidades concretas e temas que dessem conta das especificidades das sensibilidades e mentalidades na trama do cotidiano e nos conflitos ali gerados, em oposição a uma realidade universal genérica.

$\mathrm{Na}$ vereda aberta por esta perspectiva, encontramos as noçóes de cultura no plural e de invenção do cotidiano, propostas por Michel de Certeau e que neste artigo nos interessam de maneira particular, pela contribuição que trazem para pensarmos nas apropriaçóes e sensibilidades elaboradas na vida diária das crianças e jovens que analisamos.

Michel de Certeau (1994) elabora uma teoria dos usos sociais como formuladores de "maneiras de fazer" ou formas de apropriação, em que o cotidiano surge como lugar possível de apreensão de papéis informais e formas de resistência e réplica que escapam aos papéis prescritos, nesta multiplicidade de mediaçóes na vida de todo dia, ressaltando a margem de resistência possível, a improvisaçáo, a capacidade de subverter os padrôes impostos (DIAS, 1998). Há no cotidiano, segundo o autor, uma outra lógica - aquela dos usos - que náo necessariamente corrobora a lógica dominante dos meios, das instituiçôes. Modos de ver, escutar, consumir caracterizados pela noção de tática e não de estratégia. Enquanto esta última é entendida como ação calculada dos dominantes (por possuir um local próprio e por ser a arte do forte), as táticas são os modos de operação e luta daqueles que não têm um lugar próprio: a arte do fraco, permeada 
pelos contextos, situações e ocasiōes que levam ao improviso, o não calculado. São as chamadas "artes de fazer" (CERTEAU, 1994) que se mostram como possibilidades de desvio, de fuga às imposiçóes, numa forma de transformar o que é dado pela cultura oficial em astúcia cotidiana de fuga aos padróes convencionais, de maneira subliminar, não assumida e nem sempre completamente explícita. Estas possibilidades de ação e subversão estariam, segundo Certeau, no cotidiano das culturas populares, não pensadas em seu sentido autêntico ou puro, mas na conflitiva, mestiça e híbrida cultura popular urbana.

Não se trata de imaginar um cotidiano permeado por formas de resistência organizadas, conscientes e explícitas com sujeitos autônomos e independentes do que lhes é imposto, o que estaria apenas celebrando acriticamente a recepção e retirando a utilidade e potência que a vida do dia a dia pode conter. O que Certeau sugere, de maneira mais profunda, sutil, e também mais difícil de ser interpretada, é uma compreensão do cotidiano que articula, por um lado, a violência da ordem se transformando em tecnologia disciplinar, mas, por outro lado, a possibilidade de existência de uma rede de antidisciplina, de jogo, resistência e reconfiguração.

Esta noção de cotidiano colabora na compreensão da realidade tal como aqui a estamos percebendo, ou seja, na qual mensagens, narrativas, sons, imagens chegam aos receptores gerando uma formulação de sentidos e de usos em sua vida diária, organizando maneiras de ser, agir, construir identidades, sociabilidades e gerar sentidos que nem sempre são aqueles esperados pelo campo da produção midiática ou mesmo pelos discursos normativos e hegemônicos.

Certeau insistia numa abordagem que ultrapassasse o estudo da reprodução, repressão e do disciplinamento do cotidiano - tal como fora elaborado por Michel Foucault ou Pierre Bourdieu - e buscasse interpretar as práticas de sobrevivência, que se configuram como fontes de resistência,

as formas sub-reptícias que são assumidas pela criatividade dispersa, tática e bricoladora dos grupos, [estas] maneiras de fazer [que] constituem as mil práticas pelas quais usuários se apropriam do espaço organizado pelas técnicas de produção sociocultural (CERTEAU, 1994, p. 41).

Mostra-se assim, um caminho ou opção analítica, um debruçar sobre as possibilidades de resistência dos sujeitos às açôes disciplinadoras e normativas dos meios de comunicação de massa, exumando as formas táticas e bricoladoras que assumiam a criatividade dos consumidores em seu cotidiano. No entanto, este é um trabalho árduo, na medida em que estas práticas de fuga ao que é imposto estão dispersas no cotidiano, necessitando de um esforço interpretativo por parte do pesquisador para serem apreendidas, pois, embora existentes e atuantes, são muitas vezes não organizadas encobertas por uma aparência cada vez mais homogeneizante.

Neste sentido, o estudo do cotidiano vai evidenciando-se como uma possibilidade de crítica da Ciência (DIAS, 1998), em seu viés totalizante e que se quer legítimo, articulado à Razão fundadora ocidental, trazendo à tona outros objetos, métodos e perspectivas de reflexão presentes no imprevisto, fragmentário e fortuito dia a dia. A busca por aspectos dissidentes das açôes, imaginários e sensibilidades 
dos sujeitos, nos quais fluxos contra-hegemônicos podem ser interpretados, traz à tona a dimensão política do cotidiano e de seu estudo. Como lembra Dias (1998), uma "hermenêutica do cotidiano" pode trazer à luz aquilo que o poder e a ordem dos discursos hegemônicos não permitem evidenciar, um método de compreensão (e não de explicação) da realidade que busca ler nas entrelinhas, nos indícios e nos aspectos fortuitos do cotidiano, as diferenças e as fugas.

Refletir sobre o cotidiano parece ser um caminho profícuo para a compreensão das realidades vividas, para um repensar epistemológico das ciências humanas, como também para um posicionamento político/intelectual que busque as diferenças, mudanças, rupturas, possibilidades de novos modos de ser e de agir. Lembrando Perrot (1998), "ali [na vida diária dos sujeitos] onde o psicólogo das multidóes do passado via apenas massas amorfas a serem domesticadas, os indivíduos, solidários na sua solidão, dissipam as brumas e frustram o déspota."

Tendo no horizonte estas leituras da relação entre experiência e cotidiano, iremos a seguir usá-las como bússola na aproximação com um circuito específico de consumo midiático e, suspeitamos, ele confirmará múltiplos enfrentamentos da "legitimidade" como valor - social, estético, político, sensível, epistemológico.

\section{Sobre consumo midiático, cotidiano, imaginário e experiências vitais}

Nas bordas da periferia de Santos, município litorâneo de São Paulo, concentra-se a maior favela em palafitas do Brasil, o Dique da Vila Gilda. Definida como "aglomeração densa e desordenada em propriedade alheia", a favela é o reflexo de uma geografia de exclusão, constituída por centenas de moradias improvisadas de madeira, perfiladas sobre uma extensão de manguezal, cujo acesso se dá pelos becos estreitos que bifurcam dos limites do solo "terrestre" urbano.

Em meio a essa zona deserdada da cidade, um grupo de crianças e adolescentes protagoniza a pesquisa de campo, conduzida por Rezende (2015), que inspira esse artigo. Equilibrando-se entre os estigmas territoriais da periferia (WACQUANT, 2006) e as questôes de ruptura familiar, violência e drogas, esses atores sociais ${ }^{6}$ evidenciam a potência das narrativas midiáticas do entretenimento como modo de transpor a dura realidade de quem vive às margens da sociedade citadina.

Ao acompanhar esse grupo em seus trajetos do beco para o espaço de acolhimento no qual para ele são desenvolvidas atividades de lazer, cultura e espiritualidade, percebeu-se a forte presença do fenômeno midiático da periferia - o funk ostentação, o som do beco - evocado constantemente pelo batuque das mãos sobre toda e qualquer superfície mais rígida do espaço e do corpo; do ritmo reverberado no passinho do romano ${ }^{7}$; nos gestos de empoderamento dos braços que seguem os embalos das rimas, e na impostação da voz que exclama "a nave", "a novinha" e a "vida diferenciada em Guarujá".

Com efeito, as produçôes do funk ostentação se revelam numa proposta estética, social e cultural que possui uma dimensão transgressora, ao apropriar-se de signos restritos historicamente a uma elite social, e predominantemente branca, atribuindo outro sentido a esse universo simbólico a partir do cotidiano da periferia. Nessa ambivalência estética bastardizada (RINCÓN, 2015), 
o periférico transborda e esmaece as delimitaçóes territoriais: o beco chega à beira mar; o carro de luxo é integrado à paisagem da quebrada ${ }^{8}$; o cordão de ouro reluz a existência do garoto que, há tempos, era relegado à invisibilidade ou à condição estigmatizada da marginalidade.

Esse jogo de explicitar, exortar e profanar o dicotômico é sacramentado, com ênfase, nos videoclipes do funk ostentaçáo que, por sua vez, potencializam a transposição imaginária das experiências de vida no beco para outra ordem de sentidos. Assim, o vídeo torna-se extensão da alma; a forma narrativa que explora emoçóes, afetos, sonhos, subjetividades, em seu potencial expressivo (RINCÓN, 2006). No cerne desse caminho transitório entre a paisagem da pobreza e a imagem sonora da ostentação, a membrana translúcida da tela é o que aproxima e isola; faz do globo ocular a porta de entrada para outros mundos possíveis e imaginários (MORIN, 2006).

Corroborando essa reflexão, recorremos a Morin (2006, p. 77) para dizer que "[...] é por meio do estético que se estabelece a relação de consumo imaginário". Tal constatação se faz claramente evidente no funk ostentação, haja vista a potência criativa da imaginação encontrada nas performances audiovisuais desse estilo musical. Endossando essa discussão, o antropólogo Alexandre Barbosa Pereira (2015) esclarece que o luxo ostentado nas produçóes musicais do funk ostentação, a exemplo das mansóes, iates e carros, diz respeito a uma realidade mais imaginada pelos Mc's do que verdadeiramente "real", embora alguns desses artistas consigam ter acesso efetivo ao mundo de consumo que celebram nas músicas e videoclipes.

Este caráter performativo de imaginários e subjetividades nas narrativas midiáticas do entretenimento é compreendido, na visão de Rincón (2006, p. 47; tradução nossa), como “[...] um recurso para inovar a rotina diária e encantar a existência”. Eis aqui, na complexidade dessa trama de sentidos e regimes afetuais, o ponto de confluência entre o cotidiano das crianças e adolescentes do Dique da Vila Gilda e o consumo midiático das produçôes audiovisuais do funk ostentação. Para levar a cabo esta reflexão, trazemos ao diálogo um dos exemplos de videoclipes favoritos definidos pelo grupo de crianças e adolescentes das palafitas: a música Com dinheiro tudo é mais fácil, do Mc Bó do Catarina.

Em linhas gerais, a produção audiovisual apresenta a ascensão do Mc da pobreza extrema, representada pela figuração do artista como pedinte ou vendedor nas ruas e faróis da cidade, para a vida de luxo e ostentação regada a bebidas, belas mulheres (loiras, em sua grande maioria), lanchas na marina em Guarujá, carros importados e entrada vip no baile funk. Trata-se, portanto, de uma narrativa de enfrentamento ambivalente e sarcástico, na medida em que o discurso neoliberal, capitalista e de distinção introjetado nas audiovisualidades é construído de maneira irônica e desafiadora: os que ostentam também desprezam os signos monetários, como na cena paradigmática na qual o Mc, com seu grupo de amigos, literalmente jogam para o alto centenas de cédulas. E o que, afinal, se obtém da narrativa midiática em questão? Vejamos: da condição marginal, invisível e estigmatizada, o Mc Bó do Catarina atinge projeção e distinção social, e conquista novos espaços urbanos, públicos e privados: aqui desponta o cidadão celebridade da cultura bastarda (RINCÓN, 2015), protagonista de sua existência e promotor da periferia que sonha, alcança, consome e ostenta. 
No mundo colorido9 da riqueza este corpo juvenil, adolescente, muda de lugar. Se, antes, parado nos faróis da cidade, era espectador do deslocamento alheio, ele, agora, tem direito e poder de deslocamento. Ao retratarem a ascensão social o fazem associando-a a riqueza, aos bens monetários - o ouro, o dinheiro e materiais - o carro, a lancha, as roupas. Sua estética da visibilidade é paradoxal: louvam valores dos "abastados" ao mesmo temo em que denunciam a fragilidade e superficialidade dos vínculos gerados neste estilo de vida que, eles o sabem, não é o mesmo em que foram criados. Os jovens protagonistas do "ostentação" são os atores de seus próprios vídeos, são coreógrafos de sua própria performance existencial. Transitam pelo mundo das posses - e, neste caso, é flagrante e ostensiva a objetualização do corpo feminino ${ }^{10}$ - mas não abandonam seus pertencimentos de origem - os amigos, o beco, as culturas da periferia.

Subvertendo a lógica da periferia que é suprimida e sujeita à invisibilidade e à exclusão, o cidadão celebridade do funk ostentação constrói imaginários diaspóricos pela performance audiovisual; transborda a precariedade cotidiana para atuar além das bordas, em contextos pós-periféricos (ROCHA; SILVA; PEREIRA, 2015). Nessa linha de raciocínio, o consumo midiático desse fenômeno cultural pelas crianças e adolescentes, especialmente aquelas que vivem em condiçôes de vulnerabilidade social extrema, é compreendido como uma tática de sobrevivência ao e no cotidiano do beco; transcendência imaginária que possibilita outras formas de pertencimento em universos distintos.

Essa experiência sensível é revelada nas artes de fazer da vivência do beco, expressa nas conversaçôes sobre sonhos de "quando eu crescer", nas coreografias e cantorias que divertem e solidificam uma armadura corpórea para o desafio diário de viver em meio ao precário. Novamente Morin (2006, p. 71) ensina: "[...] nós nos expressamos e conhecemos o outro evocando aquilo em que nós projetamos”. Indo além, o autor ressalta: “[...] os sucos que penetram através das membranas televisuais purgam e irrigam simultaneamente a personalidade e a própria vida do homem moderno" (2006, p. 72).

Assim, ao relacionar a jornada empírica, brevemente apresentada em nosso diálogo, com as reflexôes tecidas sobre o cotidiano e a partilha do sensível, coexistentes nos processos comunicacionais e de consumo midiático, buscamos abrir uma outra perspectiva possível para compreender as partilhas do sensível articuladas por estas narrativas midiáticas do ostentação, sabendo-as implicadas em contextos de recepção desse fenômeno da periferia. $\mathrm{O}$ tensionamento entre a narrativa de entretenimento do funk ostentação e a realidade precária das crianças e adolescentes do Dique da Vila Gilda evidencia a complexidade das teias de sentido que engendram os circuitos de produção e circulação midiática, demandando, portanto, o rompimento com análises moralistas e condicionadas sobre a periferia, mas, com urgência, oferecendo novas perspectivas epistemológicas que contemplem as complexas dimensóes do cotidiano e do sensível dessa realidade. E o caminho parece ser claro: auscultar a voz que ali se vocaliza. Mesmo que ela não agrade, mesmo que surpreenda e desloque os analistas de seus lugares de conforto. 


\section{Referências bibliográficas}

AMADO, Adriana e RINCÓN, Omar. La comunicación en mutación. Bogotá: Fundación Friedrich Ebert (FES), 2015. http://www.fesmedia-latin-america.org/uploads/media/FINAL_Comunicacion_en_mutacion.pdf (Acesso em 9/11/2015).

CANEVACCI, Massimo. Fetichismos visuais: corpos erópticos e metrópole comunicacional. São Paulo: Ateliê Editorial, 2008.

CERTEAU, Michel de. A invenção do cotidiano: 1. Artes de fazer. Petrópolis: Vozes, 1994.

CORSARO, William A. Sociologia na infância. Porto Alegre: Artmed, 2011.

DIAS, Maria Odila Leite. "Hermenêutica do cotidiano na historiografia contemporânea”. Projeto História - Trabalhos da memória. São Paulo: Educ, n.17, 1998, pp. 223-258.

GOMES, Itânia. "Raymond Williams e a hipótese cultural da estrutura de sentimento". In: JANOTTI, JR. Jéder e GOMES, Itânia (orgs). Comunicação e Estudos Culturais. Salvador: Ed. UFBA, 2011.

HELLER, Agnes. O cotidiano e a História. Rio de Janeiro: Paz e Terra, 1985.

HERSCHMMAN, Micael. "La música como potente forma de comunicación”. In: AMADO, Adriana e RINCÓN, Omar. La comunicación en mutación. Bogotá: Fundación Friedrich Ebert (FES), 2015.

MORIN, Edgar. Culturas de massas no século XX. Volume 1: neurose. Rio de Janeiro: Forense, 2006.

PEREIRA, Alexandre Barbosa. "Funk ostentação em São Paulo: imaginação, consumo e novas tecnologias da informação e da comunicação". Revista Estudos Culturais, São Paulo: Programa de Pós-Graduação em Estudos Culturais da Escola de Artes, Ciências e Humanidades da Universidade de São Paulo, v.1, n.1., 2015. Disponível em: http://each. uspnet.usp.br/revistaec/?q=revista/1/funk-ostenta\%C3\%A7\%C3\%A3o-em-s\%C3\%A3o-paulo-imagina\%C3\%A7\%C3\%A3o-consumo-e-novas-tecnologias-da-informa\%C3\%A7\%C3\%A3o-e-da. (Acesso em 1/8/2015).

PERROT, Michelle. "Mil maneiras de caçar”. Projeto História - Trabalhos da memória. São Paulo: Educ, n.17, 1998, pp. 55-61.

PROUT, Alan. "Reconsiderando a nova sociologia da infância”. 2011. Disponível em: http://www.scielo.br/pdf/cp/v40n141/v40n141a04.pdf. (Acesso em 20/7/2015)

RANCIÈRE, A partilha do sensivel. São Paulo: Editora 34, 2009.

REZENDE, Aline. ENTRE O OLHAR DA POBREZA E O SOM DA OSTENTAÇÃO: as narrativas midiáticas do funk ostentação na vivência das infâncias em contextos de vulnerabilidade social. Dissertação de mestrado (em andamento, sob orientação de Rose de Melo Rocha). São Paulo: PPGCOM-ESPM. 
RINCÓN, Omar. Narrativas mediáticas: o como se cuenta la sociedade del entretenimiento. Barcelona: Gedisa Editorial, 2006.

RINCÓN, Omar. "Lo popular en la comunicación: culturas bastardas + ciudadanías celebrities”. In: AMADO, Adriana e RINCÓN, Omar. La comunicación en mutación. Bogotá: Fundación Friedrich Ebert (FES), 2015.

ROCHA, Rose de Melo. "Corpos significantes na metrópole discursiva: ensaio sobre fetichismo visual e ativismo juvenil”. Revista Significação, n. 37, ano 39, 2012. http://www.revistas.usp.br/significacao/article/ view/71333/74339 (Acesso em 15/10/2015).

ROCHA, Rose de Melo. "Imagens limiares: primeiras fundamentaçôes parauma imagética do consumo". Cadernos de Pesquisa ESPM, São Paulo, v. 1, n. 4, 2009.

ROCHA, Rose de Melo, SILVA, Josimey Costa, PEREIRA, Simone Luci. "Imaginários de uma outra diáspora: consumo, urbanidade e acontecimentospós-periféricos. Galaxia (São Paulo, Online), n. 30, p. 99-111, dez. 2015. http://dx.doi.org/10.1590/1982-25542015220453 (Acesso em 19/11/2015).

SOARES, Thiago. A estética do videoclipe. João Pessoa, Editora da UFPB, 2013.

WACQUANT, Loïc. "A estigmatização territorial na idade da marginalidade avançada". In: Revista da Faculdade de Letras do Porto, série I, vol. 16, 2006, pag. 27-39.

\section{Notas}

1. Entendemos por politicidade a ação consciente e autônoma que objetiva a transformação de si e da sociedade, envolvendo exercícios cotidianos de reflexão e intervenção que mobilizam fortemente o corpo e a capacidade/possibilidade de comunicação. Politicidade remete, portanto, a um âmbito de exercício político, de sensibilidade, socialidade e de subjetivação que ultrapassa e pode confrontar o plano institucional. O conceito tem sido desenvolvido por Rocha (2012) em suas investigaçôes sobre políticas de visibilidade e ativismos contemporâneos.

2. Para uma análise complexa e original da experiência estética articulada pelos videoclipes consultar Soares (2013).

3. Uma problematização importante relacionada ao consumo midiático de narrativas audiovisuais envolve o debate sobre fetichismo, em especial sobre suas conformaçóes e atualizaçóes contemporâneas. Aqui, lembramo-nos de Canevacci (2008), quando propóe o exercício da "estupefação" como tática de observação e análise dos fetichismos visuais

4. Juntamente com Georg Lukacs, Agnes Heller fez parte da chamada Escola de Budapeste, grupo de intelectuais que elaborou um marxismo crítico no leste europeu.

5. Denominação utilizada pelo Instituto Brasileiro de Geografia e Estatística (IBGE) para domicílios ocupados em favelas, invasōes, grotas, baixadas, comunidades, vilas, ressacas, mocambos, palafitas, entre outros assentamentos irregulares no país. 
6. O caráter de atores sociais atribuído às infâncias está fundamentado nos estudos da nova sociologia da infância de Alan Prout (2010) e William Corsaro (2011). Nessa perspectiva, a infância é concebida por meio de uma construção social, constituída por seus significados culturais e formas de sociabilidade, contrapondo-se à universalidade de seu caráter histórico e sujeição adultocêntrica, atuando ativamente em meio às dinâmicas sociais.

7. Estilo de dança performativa do funk, originada no Jardim do Romano, na Zona Leste de São Paulo. Para mais informaçôes, ver: http://www1.folha.uol.com.br/ cotidiano/2014/06/1470683-com-danca-de-robo-passinho-do-romano-vira-febrena-periferia-de-sp.shtml. (Acesso em: 12/11/2015).

8. Expressão utilizada pelos Mc’s para se referir às ruas e becos da periferia.

9. Neste videoclipe há uma oposição clara: as cenas do "antes", do protagonista em situação precária, pedindo dinheiro e vendendo nos faróis, estão em preto e branco; as cenas que o retratam já "com dinheiro e fama” são em cores.

10. As representaçôes do corpo feminino e das mulheres nos clipes do funk ostentação merecem um estudo à parte, que nos interessa desenvolver em outras publicaçôes. Pois, se podemos considerar que enfrentam e subvertem dinâmicas de subalternidade, também notamos, neste caso em articular, que reiteram ordens patriarcais, em suas atualizaçóes neoliberais e neotriunfalistas. 